\begin{tabular}{|c|c|c|}
\hline Case Reports in & \multicolumn{2}{|c|}{ Case Rep Gastroenterol 2018;12:679-685 } \\
\hline Gastroenterology & $\begin{array}{l}\text { DOI: } 10.1159 / 000494918 \\
\text { Published online: November 28, } 2018\end{array}$ & $\begin{array}{l}\text { (c) } 2018 \text { The Author(s) } \\
\text { Published by S. Karger AG, Basel } \\
\text { www.karger.com/crg }\end{array}$ \\
\hline & $\begin{array}{l}\text { This article is licensed under the } \mathrm{Cr} \\
\text { International License (CC BY-NC) (ht } \\
\text { Usage and distribution for commercial }\end{array}$ & $\begin{array}{l}\text { nons Attribution-NonCommercial } 4.0 \\
\text { ger.com/Services/OpenAccessLicense). } \\
\text { uires written permission. }\end{array}$ \\
\hline
\end{tabular}

\title{
Successful Endoscopic Closure Using Polyglycolic Acid Sheets with Fibrin Glue for Nonhealing Duodenal Ulcer with Perforation after Proton Beam Therapy of Liver Tumor
}

\author{
Ko Watanabe ${ }^{a, b}$ Takuto Hikichi ${ }^{a}$ Jun Nakamura ${ }^{a, b}$ \\ Minami Hashimoto ${ }^{a, b} \quad$ Tadayuki Takagi $^{b} \quad$ Rei Suzuki ${ }^{b}$ \\ Mitsuru Sugimoto $^{b} \quad$ Naoki Konno $^{b}$ Mika Takasumi $^{b}$ Yuki Sato ${ }^{b}$ \\ Hiroki Irie $^{b}$ Takashi Kimura $^{c}$ Akira Kenjo ${ }^{c}$ Shigeru Marubashi ${ }^{c}$ \\ Katsutoshi Obara ${ }^{d}$ Hiromasa Ohira $^{b}$ \\ aDepartment of Endoscopy, Fukushima Medical University Hospital, Fukushima, Japan; \\ bDepartment of Gastroenterology, Fukushima Medical University School of Medicine, \\ Fukushima, Japan; 'Department of Hepato-Biliary-Pancreatic and Transplant Surgery, \\ Fukushima Medical University School of Medicine, Fukushima, Japan; dDepartment of \\ Advanced Gastrointestinal Endoscopy, Fukushima Medical University, Fukushima, Japan
}

\section{Keywords}

Duodenal ulcer · Endoscopy · Perforation · Polyglycolic acid · Proton beam therapy

\begin{abstract}
We describe the first case of a nonhealing duodenal ulcer with perforation after proton beam therapy (PBT) of a liver tumor that was successfully treated endoscopically using polyglycolic acid (PGA) sheets with fibrin glue. A 69-year-old man received PBT for a liver tumor. Esophagogastroduodenoscopy (EGD) 3 months after PBT revealed a duodenal ulcer. A proton pump inhibitor was administered for 7 weeks, and the ulcer healed. Six months after the EGD, recurrence of the duodenal ulcer with perforation occurred. An emergency open surgery with placement of the omental patch was performed. However, 5 days after the surgery, because the EGD revealed a perforation site in the duodenal ulcer that was not closed, the conservative
\end{abstract}




\section{Case Reports in Gastroenterology}

Case Rep Gastroenterol 2018;12:679-685

DOI: $10.1159 / 000494918$

(c) 2018 The

www.karger.com/crg

Watanabe et al.: Successful Endoscopic Closure Using Polyglycolic Acid Sheets with Fibrin Glue for Nonhealing Duodenal Ulcer

treatment was continued. Twenty-eight days after the surgery, EGD revealed that the perforation size had increased. Therefore, we conducted endoscopic closure therapy using PGA sheets with fibrin glue. Eleven days after the closure procedure, the EGD showed that the perforation site was filled with granulation tissue and was closed. Forty-nine days after the procedure, EGD revealed that the ulcer had healed. This endoscopic closure treatment was effective for a nonhealing duodenal ulcer with perforation after PBT of a liver tumor.

(C) 2018 The Author(s)

Published by S. Karger AG, Basel

\section{Introduction}

Surgical repair, usually with suturing of the defect and placement of either an omental patch or a round ligament from the liver, has been the mainstay for the management of peptic ulcer perforation [1]. Recently, a few researchers have reported cases in which gastric and duodenal ulcer perforations were closed endoscopically using polyglycolic acid (PGA) sheets with fibrin glue [2, 3]. In addition, Takimoto and Hagiwara [4] reported endoscopic treatment using PGA sheets with fibrin glue for postoperative gastric perforation of endoscopic submucosal dissection (ESD). However, the reports of this endoscopic treatment are still limited. Herein, we experienced a case with nonhealing duodenal ulcer with perforation after proton beam therapy (PBT) of a liver tumor that was successfully closed endoscopically using PGA sheets with fibrin glue. To the best of our knowledge, this is the first case report in which PGA sheets were used for the treatment of ulcer perforation after PBT. Moreover, we tracked the healing process of ulcer perforation endoscopically over time.

\section{Case Report}

A 69-year-old man with no remarkable history received PBT (total dose of 74 GyE) for a liver tumor (intrahepatic bile duct cancer) in a previous hospital. Esophagogastroduodenoscopy (EGD) 3 months after PBT revealed a large duodenal ulcer in the duodenal bulb, which was considered to be a late adverse event of PBT. A proton pump inhibitor (PPI) after EGD was administered for 7 weeks, and the ulcer healed. Six months after the EGD, the patient was transferred to our hospital due to severe abdominal pain. Computed tomography (CT) showed free air and fluid collection around the liver, suggesting perforation of the gastrointestinal tract. EGD demonstrated the recurrence of the duodenal ulcer with perforation. Emergency open surgery with placement of an omental patch and abdominal drainage was performed. However, the accompanying fever did not subside, and white blood cells and C-reactive protein in blood tests remained high after the surgery. Five days after the surgery, EGD revealed that the perforation in the duodenal ulcer was not closed. During that time, fasting, indwelling of a nasogastric tube, intravenous broad-spectrum antibiotics, and a PPI were maintained. Twelve days after the surgery, CT demonstrated an abscess around the liver, and a percutaneous drainage tube was inserted. The clinical signs of the patient and the laboratory findings, including white blood cells and C-reactive protein, in blood tests improved after the procedure. However, 28 days after the surgery, EGD revealed that the perforation had increased in size by approximately $10 \mathrm{~mm}$ (Fig. 1). Reoperation could not be performed due to the patient's malnutrition. Thus, after obtaining written informed consent from the patient about the endoscopic closure of the duodenal perforation, we endoscopically closed the duodenal perforation using PGA sheets with fibrin glue in accordance with Takimoto and Hagiwara's method 


\section{Case Reports in Gastroenterology}

Case Rep Gastroenterol 2018;12:679-685

DOI: $10.1159 / 000494918$

(c) 2018 The Author(s). Published by S. Karger AG, Basel www.karger.com/crg

Watanabe et al.: Successful Endoscopic Closure Using Polyglycolic Acid Sheets with Fibrin Glue for Nonhealing Duodenal Ulcer

[4]. A $100 \times 50 \mathrm{~mm}, 0.15-\mathrm{mm}$ thick PGA sheet (Neoveil, Gunze Corp., Kyoto, Japan) was cut into $10 \times 10 \mathrm{~mm}$ pieces and $20 \times 10 \mathrm{~mm}$ pieces. Then, $10 \times 10 \mathrm{~mm}$ pieces of PGA sheets were placed over the perforation site with a biopsy forceps (EndoJaw, FB-230K, Olympus Medical Systems Corp., Tokyo, Japan) through the channel of the endoscope (GIF-H290, Olympus Medical Systems Corp.) 6 times (Fig. 2a). After the pieces of the PGA sheets were packed into the perforation, the lesion around the perforation site was sufficiently covered with $20 \times 10 \mathrm{~mm}$ pieces (Fig. 2b). Finally, the PGA sheets were fixed in place with fibrin glue (Beriplast P CombiSet, CSL Behring, USA). Fibrin glue was applied using a spray tube through the channel of the endoscope. We did not fix the PGA sheets using additional endoclips, unlike previous reports of peptic ulcer perforation $[2,3]$. The procedure time for filling and shielding using PGA sheets with fibrin glue took $20 \mathrm{~min}$, and there were no adverse events.

Four days after the endoscopic procedure, the EGD showed that the PGA sheet covered the ulcer and perforation site (Fig. 3a). Eleven days after the procedure, the EGD showed that the perforation site was filled with granulation tissue and was closed (Fig. 3b). Therefore, oral intake was resumed, and PPI was administered orally. Twenty-five days (Fig. 3c) after the procedure, EGD showed thicker granulation tissue extending to the surface of the ulcer around the perforation site, and the PGA sheet was gradually absorbed. Forty-nine days after the procedure, EGD revealed that the ulcer had healed, and the PGA sheet was completely absorbed (Fig. 3d).

\section{Discussion}

This report described successful endoscopic treatment using PGA sheets with fibrin glue for a nonhealing duodenal ulcer with perforation after PBT of a liver tumor. A previous study reported that gastroduodenal ulcers occurred in 2\% of the patients after PBT for liver tumors [5]. Another study reported fatal gastric perforation after PBT for liver tumors [6]. In our report, the ulcer perforation after PBT was not closed after surgery with placement of the omental patch and conservative treatment for a long period. Thus, we tried to treat the duodenal perforation endoscopically using PGA sheets with fibrin glue. The ulcer perforation was closed within a short period after the procedure.

The PGA sheet is a bioabsorbable synthetic polymer that enhances the strength of sutures. Therefore, PGA sheets have been widely used in multiple surgical fields to treat multiple conditions, such as postoperative pulmonary fistulas $[7,8]$. The coating effect of the PGA sheet is enhanced when the sheets are affixed with fibrin glue. Recently, in the field of gastrointestinal endoscopy, shielding for artificial ulcers after ESD for gastrointestinal neoplasms using PGA sheets with fibrin glue has also been reported [9-11]. In addition, the filling and shielding for peptic ulcer perforation and delayed perforation after ESD using PGA sheets have been reported [2-4]. PGA sheets serve as a scaffold function to induce better granulation formation for tissue regeneration. Granulation tissue fills the perforation site, generating scaffolds that can promote their closure $[4,12]$. Additionally, PGA sheets have been reported to become naturally hydrolyzed and absorbed within approximately 15 weeks [9]. Therefore, they are not recognized as foreign substances.

In our case, granulation tissue formed from the perforation site at an early period; consequently, the perforation was closed 11 days after the endoscopic procedure. Following the closure of perforation, thicker granulation tissue extended to the surface of the ulcer around the perforation site. In the field of regenerative medicine, inflammation is considered to be essential for regeneration [13]. Thus, Takimoto and Hagiwara [4] reported that inflammation 
of the perforation might have contributed to the early formation of granulation tissue. Based on the knowledge of regeneration and our temporal endoscopic observation, the sufficient filling of PGA sheets into the perforation site was considered to be important for better and earlier granulation formation.

As another method of endoscopic closure for perforation of the gastrointestinal tract, the effectiveness of endoscopic closure using the over-the-scope-clip (OTSC) system has been reported $[14,15]$. However, it is often difficult to close the lesion with edema, inflammation, severe fibrosis, and scarring using the OTSC [15]. Compared with endoscopic closure using the OTSC, filling and shielding using PGA sheets with fibrin glue is technically easy to perform for peptic perforated ulcers with inflammation or severe fibrosis.

In conclusion, filling and shielding using PGA sheets with fibrin glue was effective for a nonhealing duodenal ulcer perforation after PBT for a liver tumor.

\section{Acknowledgments}

We wish to express our deep appreciation to all endoscopy medical staff for their assistance with endoscopic procedures.

\section{Statement of Ethics}

All procedures have been performed in accordance with the ethical standards laid down in the 1964 Declaration of Helsinki and its later amendments. In addition, consent was obtained from the patient described in this article.

\section{Disclosure Statement}

The authors declare that they have no conflicts of interest in relation to this article.

\section{Author Contributions}

K. Watanabe and T. Hikichi collected the data and wrote the manuscript. K. Watanabe performed the endoscopic procedure. J. Nakamura and M. Hashimoto served as assistants during the endoscopic procedure. T. Takagi, R. Suzuki, M. Sugimoto, N. Konno, M. Takasumi, Y. Sato, and H. Irie provided clinical advice. T. Kimura and A. Kenjo managed the patient. Marubashi S, Obara K, and Ohira $\mathrm{H}$ supervised the production of the manuscript. All authors approved the final manuscript for publication.

\section{References}

1 Søreide K, Thorsen K, Harrison EM, Bingener J, Møller MH, Ohene-Yeboah M, et al. Perforated peptic ulcer. Lancet. 2015 Sep;386(10000):1288-98.

2 Han S, Chung H, Park JC, Shin SK, Lee SK, Lee YC. Endoscopic management of gastrointestinal leaks and perforation with polyglycolic acid sheets. Clin Endosc. 2017 May;50(3):293-6. 
Watanabe et al.: Successful Endoscopic Closure Using Polyglycolic Acid Sheets with Fibrin Glue for Nonhealing Duodenal Ulcer

3 Mishiro T, Shibagaki K, Matsuda K, Fukuyama C, Okada M, Mikami H, et al. Successful endoscopic management of non-healing perforated duodenal ulcer with polyglycolic acid sheet and fibrin glue. ACG Case Rep J. 2016 Dec;3(4):e197.

4 Takimoto K, Hagiwara A. Filling and shielding for postoperative gastric perforations of endoscopic submucosal dissection using polyglycolic acid sheets and fibrin glue. Endosc Int Open. 2016 Jun;4(6):E6614.

5 Yu JI, Yoo GS, Cho S, Jung SH, Han Y, Park S, et al. Initial clinical outcomes of proton beam radiotherapy for hepatocellular carcinoma. Radiat Oncol J. 2018 Mar;36(1):25-34.

6 Hong TS, DeLaney TF, Mamon HJ, Willett CG, Yeap BY, Niemierko A, et al. A prospective feasibility study of respiratory-gated proton beam therapy for liver tumors. Pract Radiat Oncol. 2014 Sep-Oct;4(5):316-22.

7 Hayashibe A, Sakamoto K, Shinbo M, Makimoto S, Nakamoto T. New method for prevention of bile leakage after hepatic resection. J Surg Oncol. 2006 Jul;94(1):57-60.

8 Kawai H, Harada K, Ohta H, Tokushima T, Oka S. Prevention of alveolar air leakage after video-assisted thoracic surgery: comparison of the efficacy of methods involving the use of fibrin glue. Thorac Cardiovasc Surg. 2012 Jul;60(5):351-5.

9 Takimoto K, Imai Y, Matsuyama K. Endoscopic tissue shielding method with polyglycolic acid sheets and fibrin glue to prevent delayed perforation after duodenal endoscopic submucosal dissection. Dig Endosc. 2014 Apr;26 Suppl 2:46-9.

10 Doyama H, Tominaga K, Yoshida N, Takemura K, Yamada S. Endoscopic tissue shielding with polyglycolic acid sheets, fibrin glue and clips to prevent delayed perforation after duodenal endoscopic resection. Dig Endosc. 2014 Apr;26 Suppl 2:41-5.

11 Tsuji Y, Fujishiro M, Kodashima S, Ono S, Niimi K, Mochizuki S, et al. Polyglycolic acid sheets and fibrin glue decrease the risk of bleeding after endoscopic submucosal dissection of gastric neoplasms (with video). Gastrointest Endosc. 2015 Apr;81(4):906-12.

12 Hiroyuki T, Kohki Y, Hiroe M, Tsunehito H, Rie A, Shota T, et al. A basic study of the effect of the shielding method with polyglycolic acid fabric and fibrin glue after endoscopic submucosal dissection. Endosc Int Open. 2016 Dec;4(12):E1298-304.

13 Gurtner GC, Werner S, Barrandon Y, Longaker MT. Wound repair and regeneration. Nature. 2008 May;453(7193):314-21.

14 Verlaan T, Voermans RP, van Berge Henegouwen MI, Bemelman WA, Fockens P. Endoscopic closure of acute perforations of the GI tract: a systematic review of the literature. Gastrointest Endosc. 2015 Oct;82(4):61828.e5.

15 von Renteln D, Denzer UW, Schachschal G, Anders M, Groth S, Rösch T. Endoscopic closure of GI fistulae by using an over-the-scope clip (with videos). Gastrointest Endosc. 2010 Dec;72(6):1289-96.

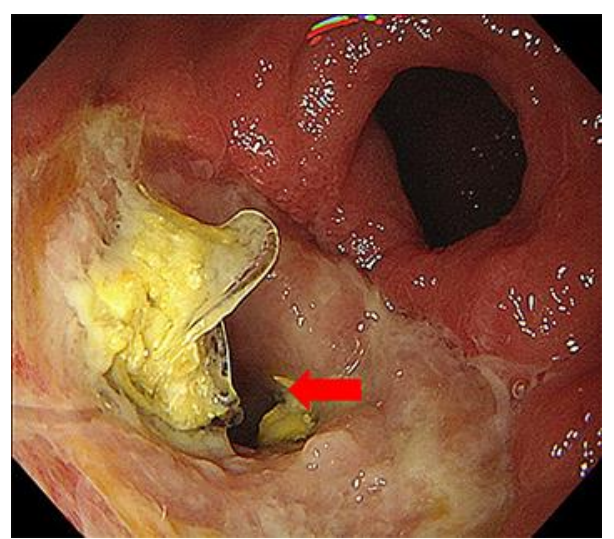

Fig. 1. An endoscopic image obtained 28 days after surgery. Esophagogastroduodenoscopy revealed that perforation had increased in size by approximately $10 \mathrm{~mm}$ (red arrow). 


\section{Case Reports in Gastroenterology}

Watanabe et al.: Successful Endoscopic Closure Using Polyglycolic Acid Sheets with Fibrin Glue for Nonhealing Duodenal Ulcer
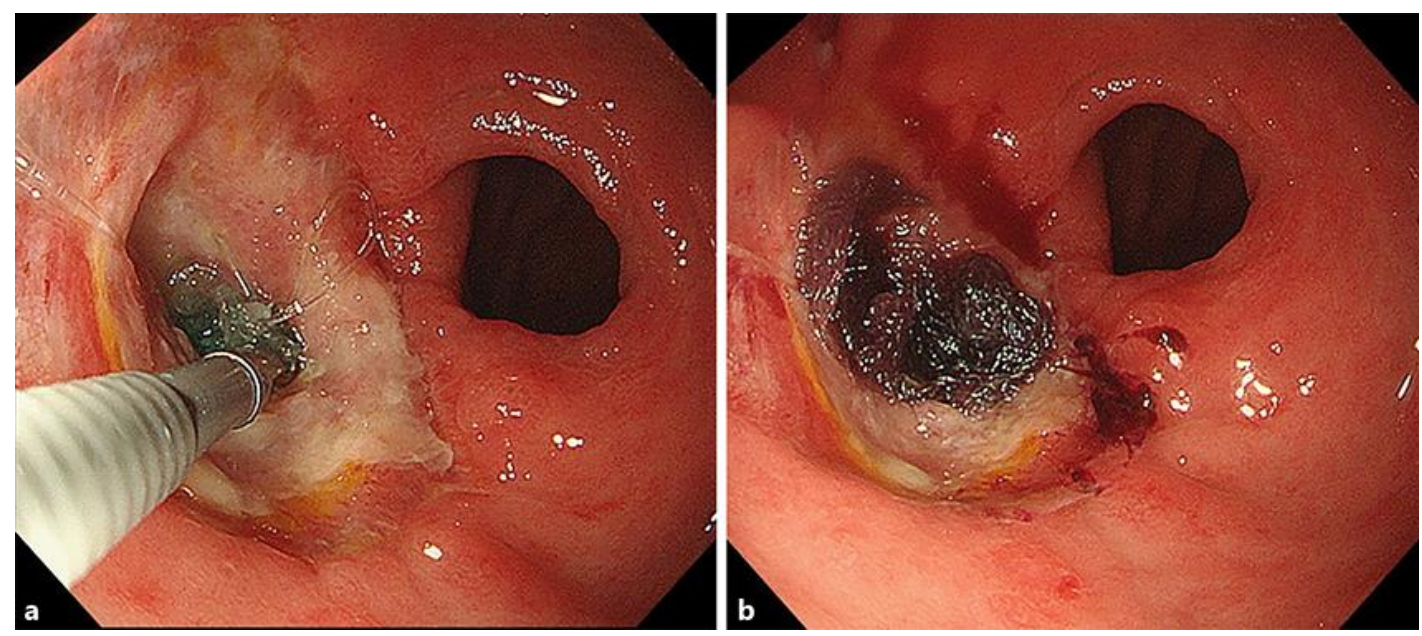

Fig. 2. a An endoscopic image obtained during the filling and shielding using polyglycolic acid sheets with fibrin glue. Then, $10 \times 10 \mathrm{~mm}$ pieces were placed over the perforation site with a biopsy forceps. $\mathbf{b}$ After the cut pieces were packed into the perforation, the lesion around the perforation site was covered with $20 \times 10 \mathrm{~mm}$ pieces. 


\section{Case Reports in Gastroenterology}

\begin{tabular}{l|l}
\hline Case Rep Gastroenterol 2018;12:679-685 \\
\hline DOI: 10.1159/000494918 & $\begin{array}{l}\text { ( ) 2018 The Author(s). Published by S. Karger AG, Basel } \\
\text { www.karger.com/crg }\end{array}$ \\
\hline
\end{tabular}

Watanabe et al.: Successful Endoscopic Closure Using Polyglycolic Acid Sheets with Fibrin Glue for Nonhealing Duodenal Ulcer
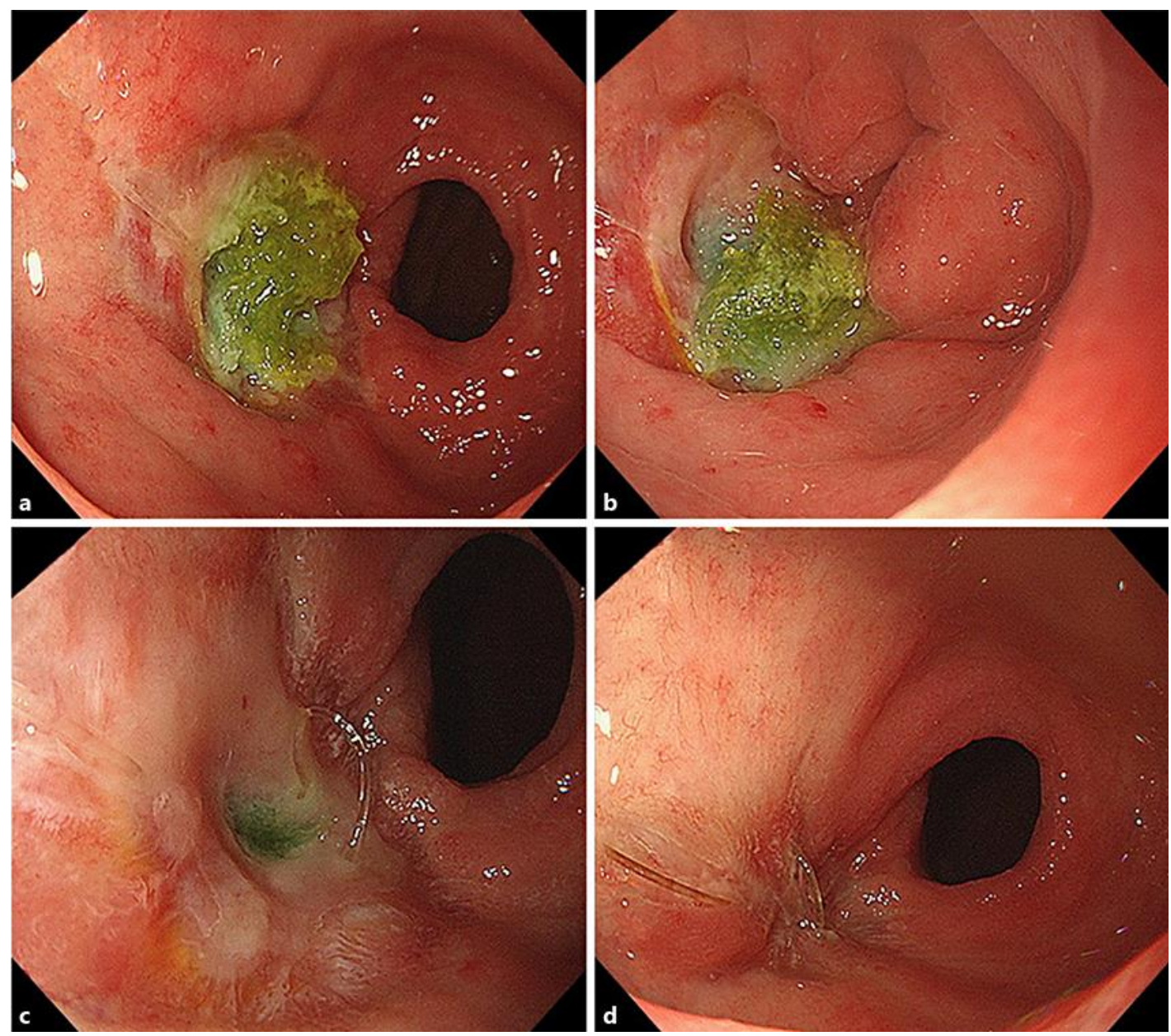

Fig. 3. a An endoscopic image obtained 4 days after filling and shielding using polyglycolic acid (PGA) sheets with fibrin glue. Esophagogastroduodenoscopy (EGD) showed a PGA sheet covering the ulcer and perforation site. $\mathbf{b}$ Eleven days after the endoscopic procedure. The EGD showed that the perforation site was filled with granulation tissue and was closed. c Twenty-five days after the endoscopic procedure. EGD showed thicker granulation tissue extending to the surface of the ulcer. $\mathbf{d}$ Forty-nine days after the endoscopic procedure. EGD revealed that the ulcer had healed and that the PGA sheet was absorbed. 